\title{
The Lived Experience of PLWHA and Partner's Responses toward the Fulfillment of Sexual Needs
}

\author{
I Gede Nyoman Ardi Supartha ${ }^{1}$, Agung Waluyo², I Made Kariasa ${ }^{3}$ \\ ${ }^{1}$ Postgraduate Program, Faculty of Nursing, University of Indonesia, Depok, Indonesia \\ ${ }^{2,3}$ Department of Nursing, Faculty of Nursing, University of Indonesia, Depok, Indonesia \\ Corresponding Author: I Gede Nyoman Ardi Supartha (ardi.supartha@gmail.com)
}

\begin{abstract}
Background: Every single person including people living with HIV/AIDS (PLWHA) have five basic needs; one of which is a physiological sexual need. Unfortunately, PLWHA face many difficulties in fulfilling their sexual needs due to the stigma and fear of infecting their partner.

Purpose: The purpose of this study was to explore the lived experience of PLWHA and partner's responses toward the fulfillment of sexual needs.

Methods: This study was a qualitative descriptive phenomenological research, which collected data through in-depth interviews from fourteen PLWHA in Paramacitta Spirit Foundation, Denpasar. The participants were recruited through snowball sampling, informed and gave consent for their voluntary participation. The data were analyzed using Colaizzi's phenomenological method.

Results: The study revealed five themes describing the sexual experiences of PLWHA, including: (1) the fulfillment of sexual need of PLWHA, (2) the roles of partner for PLWHA, (3) various perceived stimuli which could increase the sexual desire, (4) the perceived factors which could incapacitate the ability and quality of sexual desire, and (5) the efforts to increase sexual capability and quality.

Conclusion: Sex was an important need for PLWHA to meet. Despite having a virus, after undergoing anti-retroviral (ARV) treatment, PLWHA felt healthier, and thus they could meet their sexual need like a normal person in general.
\end{abstract}

Keywords: AIDS; PLWHA; sexual fulfillment; sexual need

\section{BACKGROUND}

The first HIV infection case was found in Kinshasa, Democratic Republic of Congo in 1980. Since it was first found until the end of 2014, HIV/AIDS was reported to infect around 36.9 million people around the world. Two million cases of new HIV infections and 1.2 million deaths are related to HIV. Increasing cases of HIV/AIDS occurred in the Middle East and North Africa with new total incidents of HIV infection as many as 22,000 incidents and 12,000 deaths at the end of 2014. Meanwhile, in sub-Saharan Africa, the new HIV infection was reported to decline by $41 \%$, which was formerly recorded to reach 2.3 to 1.4 million incidents. The death due to HIV infection was also reported to decrease by $34 \%$ from 1.2 million deaths to 790 thousand births. A similar situation was also found in the Caribbean, America Latin, Europe, and Asia Pacific (Joint United Nations Programme on HIV/AIDS [UNAIDS], 2015). 
The case of HIV infection in Indonesia was firstly found in Bali in 1987, and until now, it has spread to 386 regencies in the whole provinces in Indonesia. The highest number of HIV/AIDS infection was found in Papua with 16.051 HIV cases and 10.184 AIDS cases, with the prevalence of 359.43 incidents per 100,000 populations. The lowest figure occurred in West Sulawesi with 39 HIV new infections and 6 AIDS cases with the prevalence of 0.52 incidents per 100,000 citizens. Bali ranked fourth highest in Indonesia, and the cumulative number reached to 9,637 of HIV cases and 4,261 of AIDS with a prevalence of 109.52 incidents per 100,000 populations (Directorate General of Disease Control and Environmental Health, Republic of Indonesia [DGDC \& EH MoH RI], 2014).

The age group of 20-29 (18,352 cases) is the most dominant group with HIV/AIDS infections. Followings are the age group of 30-39 (15,890 cases) and the age group of 40-49 (5,974 cases). Males with HIV (13,280 cases) are bigger in number than women (9,589 cases). Meanwhile, the risk factor of transmission of heterosexual cases $(61.5 \%)$ become the most dominant factor followed by the use of the drug by syringe $(15.2 \%)$ and homosexual intercourse $(2.4 \%)$. The highest occupancy of HIV-infection is housewives (6,539 cases), self-employed (6,203 cases), and non-professional workers (5,638 cases) (DGDC \& EH MoH RI, 2014).

Various problems in living for PLWHA occur due to the negative stigma in public about HIV/AIDS infection which is identical to immoral behavior like free sex, drug users, and sexual intercourse. As many as $48.2 \%$ PLWHA had experienced discrimination after known infected with HIV, $12.2 \%$ experienced discrimination from relatives, $12.1 \%$ from friends, $26.2 \%$ from health workers, $18.7 \%$ from their relationship and $13.2 \%$ from workplace (Adekanle, Olowookere, Adewole, Adeleke, \& Ijadunola, 2015; Bouhnik, Preau, Schiltz, Obadia, \& Spire, 2008;). Discrimination is one of the causes of stress and depression for PLWHA (Chama, Morrupa, \& Gashau, 2007). Stress is a form of tension of physical, psychological, emotional or mental status related to a circumstance being endured while depression is an advanced stage of chronic stress which is classified as a mental disorder characterized by sad feelings, sleep disorders, appetite decreases, concentration decrease and solitude feelings (National Institute of Mental Health [NIMH], 2015).

The diagnosis of positive HIV also had an impact on PLWHA especially to those who have a lived couple. A study conducted in Morocco involving 134 PLWHA reported that $17 \%$ respondents expressed fear to have sex since they did not want to transmit the virus to their couple, whereas $18 \%$ were reported to have sexual dysfunction (Fane et al., 2011). In another study, it was reported that of 28 participants, $85.7 \%$ expressed the fear from their couples when they were known for HIV positive (Adekanle, Olowookere, Adewole, Adeleke, \& Ijadunola, 2015). Craft and Serovich (2008) stated that stress and depression experienced by the participants after they were deemed to positive HIV gave an effect on the declined sexual excitement in PLWHA. Another study also reported that there was sexual dysfunction experienced by $51 \%$ of PLWHA seeking for the treatment by ARV. About $46 \%$ of them experienced erectile dysfunction, 39\% experienced ejaculation disorder, and $27 \%$ had orgasm disorder (Collazos, 2007). 
The fulfillment of sex needs commitment and support from spouse for the willingness from both sides to reach intimacy. PLWHA who received support from their couples had better life quality of 40.746 times than those who did not (Chama, Morrupa, \& Gashau, 2007). However, Adekanle et al. (2015) reported that the participants involved in the study who received continuous support from their partner were still classified as low, i.e., only $14.3 \%$ (4 out of 28 total participants). A preliminary field interview by the researchers with two men positive with HIV in Sanur, Bali also revealed that sexual need is the need which is reasonable to be fulfilled. However, the men still sometimes found an image of fear and reluctance of being approached by their mates.

The research about the fulfillment of sexual needs for PLWHA is still rarely conducted. Moreover, the phenomenon of sexual needs still becomes a taboo topic to talk about and is multidimensional. PLWHA who currently have better life expectancy experience barriers which deny them from fulfilling their sexual needs. It is not only caused by stress and depression, but also some other factors such as partner's support and sexual dysfunction that affect the ability of PLWHA in fulfilling their sexual needs. Therefore, it is very necessary to conduct a study to explore the experience of the sexual fulfillment of PLWHA.

\section{PURPOSE}

This study aimed to describe the lived experience of PLWHA and partner's responses toward the fulfillment of sexual needs.

\section{METHODS}

This study is a qualitative descriptive phenomenological study. A snowball sampling was used to recruit the participants $(n=18)$. During the study, four participants expressed drop out since they could not be reached for the next interview; therefore, only 14 participants were fully involved in this study. The inclusion criteria were the PLWHA who joined Spirit Paramacitta Foundation in Denpasar, had a living couple of either married or in a relationship and were able to communicate with a good communication skill. The data were collected through in-depth interviews and observations. The interviews were recorded using an MP3 recorder, and the results of observations were written as the field note. The data collected from the interviews were transcribed verbatim and then analyzed using the Colaizzi's phenomenological method.

Prior to the study, the participants were informed of and gave consent for their voluntary participation. Their identities were also kept confidential. A code name of P1 to P14 was given to the participants according to the time of participation. The ethical approval of this study was received from the Ethical Committee of the Faculty of Nursing, University of Indonesia.

\section{RESULTS}

\section{Characteristics of participants}

The total participants involved in this study were 14. Most of them were males (57\%) and aged of 36-40 (57\%). All participants were heterosexual, and the majority were infected by HIV through sexual intercourse (64\%). Most of them were private 
employees (71\%) and completed the senior high school education (57\%). Table 1 shows the participant demographic profile of the study.

Table 1. Demographic profile of participants

\begin{tabular}{lrr}
\hline Demographic Profile & $n$ & $\%$ \\
\hline Sex & & \\
$\quad$ Male & 8 & 57 \\
$\quad$ Female & 6 & 43 \\
Age & 6 & 43 \\
$\quad 30-35$ & 8 & 57 \\
$\quad 36-40$ & & \\
Employment Status & 10 & 71 \\
$\quad$ Private Employees & 4 & 29 \\
$\quad$ Housewife & & \\
HIV Record & 4 & 29 \\
$\quad$ Injection Drug & 9 & 64 \\
$\quad$ Sexual Intercourse & 1 & 7 \\
$\quad$ Tattoo & & \\
Sex Orientation & 14 & 100 \\
$\quad$ Heterosexual & & \\
Educational Attainment & 5 & 36 \\
$\quad$ Elementary School & 1 & 7 \\
$\quad$ Secondary School & 8 & 57 \\
$\quad$ Senior High School & &
\end{tabular}

\section{The fulfillment of sexual need of PLWHA}

The participants in this study mentioned that ARV treatment could improve their conditions. As a result, the participants felt healthier and were able to meet their sexual needs like a normal person.

"Ehm... My sexual activity remains the same as before. I'm infected with HIV/AIDS. So, it's normal, and when I do the sexual intercourse, I just do it as normal..." (P1)

"...it (sexual fulfillment) is just the same as the other person. Moreover, when I begin to consume the medicines, I'm becoming healthy. I usually do that". (P8)

In addition, the participants also revealed that the fulfillment of sexual need was not necessarily done by coitus. Instead, they could have jokes, chats and received attention form their mates.

"It is normal; there is always a desire for sexual activity." (P10)

"...maybe, if I'm doing the sexual activity, I forgot my sickness, and it made me feel more relaxed..." (P9)

"...instead of making love, I also need attention from my wife, love, and attention..." (P1) 


\section{The partner's roles for PLWHA}

The living partner in the relationship, i.e., husband or wife, had an important meaning in the life of PLWHA. The presence of the spouse as a companion and life encouragement always provided support for PLWHA in daily life and the fulfillment of a sexual need.

"I am very grateful that my wife accompanies me in this certain condition (proud himself)." (P8)

"...my wife really supports me and has a very important role in my life. She doesn't feel worried (nodding his head), and there is no negative stigma and discrimination from her..." (P1)

“...I, with my early disability, find it very difficult to use a condom. That's why my wife helps me do that." (P10)

\section{The various perceived stimuli that could increase sexual desire}

The participants implied that some stimuli could increase their desire to have sex. The stimuli are varied such as the initiative for having sex, the attractiveness of couples, and the influence of media.

"...When having sex, I always be more active. That is what the man should do". (P2)

"...her behavior, her twitch (explaining using hand gestures), suddenly raise my desire. More often, when I see my wife in a specific dress (laughing) or when I see her wearing a sexy dress that really influences my desire (smiling)". (P7)

“...yes, I'm a man. If I see something sexy, of course, it can raise my desire. For example, if I watch a certain movie". (P8)

\section{The perceived factors that could incapacitate ability and quality of sexual intercourse}

The participants expressed several factors that could be grouped into the internal and external factor which were perceived to decrease the ability and quality of sexual intercourse of PLWHA. The internal factor consists of the lifestyle, the burden of mind, preparation, and side effects of ARV. Meanwhile, the external factors consist of the length of the marriage, the use of condoms, and the beginning of the rejection.

"...when he gets drunk; he usually drinks with my neighbor. That makes my desire decreased." (P11)

"Yes, it won't erect (laughing)." (P8)

"Scare and worried. If both of us are infected, it's a pity for my children. So that, I should use a condom." (P12)

"Yah... (exhaling). When our mood is high, and also the sexual desire raises, but there is no way to pass that desire, that is disappointing." (P7)

The efforts to increase sexual capability and quality

The participants made some efforts to overcome the internal and external problems that affect their sexual capability and the quality. These efforts include changing position, trying to a new place, and scheduling sexual activities that was not so much to do it. The 
woman participants had formerly experienced blisters when having sex caused by pubic hair friction into the pit of the vagina. Therefore, participants and couples shaved their pubis to avoid possible blister when having sex.

“...if I'm bored with a certain position; I will change to new positions like changing my mood (smiling and nodding his head), as we usually explore new things." (P6)

"Maybe he understands when I said it little bit hurts. I think it blisters because it is not shaved, but now it won't hurt anymore. We shaved it to avoid blisters (turning her face and look shy). (P5)

The majority of men expressed that they had ever drunk medicines, consumed specific foods, and used tissue enhancers and traditional massage to enhance the capacity of them when having sex. The participants are also rubbing olive oil into the pit the vagina and the penis to sleek the pit of the vagina when having sex.

"I ever consume some tablets." (P10)

"...before having sex, I usually eat an egg, goat satay (nodding his head)." (P6)

"Maybe, make it wetter to make it slippery (smiling) not hurt, not blister. I ever use olive oil to make it slip and my husband more active on it." (P5)

\section{DISCUSSION}

Different characteristics of participants indicated that they have different backgrounds. Based on the theory of DeLaune and Ladner (2011), the range of age of the participants in this study is in the middle age which means that they have good communication and can understand the communication when having an interview.

\section{The fulfillment of sexual needed of PLWHA}

The ARV treatment was reported to increase the condition of PLWHA. Thus, they can feel healthy and be able to fulfill their sexual need like normal people. The participants mentioned that they would be healthy and could control the virus as long as they consumed the ARV regularly. This statement is based on the result of research which shows the effectiveness of ARV treatment. Undergoing a routine and regular ARV treatment for three months could increase $\mathrm{CD}_{4}$ from $200 \pm 31$ to be $228 \pm 38 \mathrm{cell} / \mathrm{mm}^{3}$ (Qijian, Yi-Zhong, Fei-li, Jian, \& Xin 2014). Although it cannot cure HIV/AIDS, the treatment is shown to extend the hope and improve the life quality of PLWHA (DGDC \& EH MoH RI, 2014).

In the majority, male participants still had sexual intercourse once to twice a week. This statement demonstrates their ability to keep their sexual activity. This statement shows that PLWHA keeps doing sexual intercourse although they are diagnosed with HIV positive. Sexual fulfillment is the right of every human being regardless of a condition experienced by the human (Shapiro \& Ray, 2007; International Council on Human Rights Policy [ICHRP], 2009). The sexual right declared freedom for the individuals in expressing sexual behavior, showed interest to couples, married, and had a family line without feeling depressed and receiving any discrimination (Miller, Kismödi, Cottingham \& Gruskin, 2015). 
Sexual desire is the most dominant impulse that motivated most participants to perform sexual intercourse. Sexual desire motivates someone to do sexual intercourse in accordance with his sexual orientation (National Population and Family Planning Board [NPFPB], 2006). Sexual desire is described as a sweet boost to sexual intercourse (Muhanguzi, 2015). Sexual intercourse is considered as a physical need that is believed to relieve stress and improve sleep quality. Sexual activity can increase endorphin release in the body that gives happiness and a sense of comfort (Rowland \& Incrocci 2008). Sexual activity is a natural greatest relaxant and becomes the biggest contributor to release the endorphin when compared with other activities (Paul, Turek \& Kryger, 2008).

Six participants, in which the majority are women, argued that the fulfillment of sexual need is their obligation in their household life. Sexual intercourse which is carried out regularly is deemed to make a strong relationship between the husband and wife. It is defined as the need that the couples should meet by serving each other. Increasing happiness is believed to occur to those who still keep doing sexual intercourse with their couples (Hummel, 2010). That a wife regularly serves her husband is also regulated in culture and belief (Kaplan, 2011).

The non-coitus aspects that are fulfilled by PLWHA and are framed from their romantic attitudes include dating, giving attention, making a joke and chatting. This opinion was mentioned by 10 participants who defined those habits as romantic behaviors which make them happy and more encouraging. The fulfillment of sexual need is not only to focus on the coital activity, but there is also an aspect of non-coital sex that is expressed in case of attention, eye contact, and chatting (Stuart \& Laraia, 2005). Romanticism is an important key to keep the harmony and continuation of a relationship (Coyle, Anderson, Franks, Glassman, Walker, \& Charles, 2014).

\section{The partner's roles for PLWHA}

A partner is defined as a person who is loved, being together with, available to stay and encourage each other. The presence of a lived partner in this study is mentioned to be a reason to keep living and doing introspection. Moreover, the participants also felt guilty of spreading the virus to their couple. Encouragement is defined as a response to build up that is given by the partner in the form of words and actions. Encouragement is a response that all participants expected especially after they disclose their positive HIV to their couple. This statement is based on the theory that specifying encouragement is a mechanism given by individuals or groups to make an interaction related to the occurred situation (Cohen, 2004; Darbes, Chakravarty, Bougher, Neilands, \& Hoff, 2011).

Some forms of encouragements given by partner in the fulfillment of sexual need are giving reminders to take ARV, and providing and pairing condom to men before doing sexual intercourse. Furthermore, in addition to self-awareness, the use of condom for men when having sex is also influenced by the boosting of their couple. The other partner's roles expressed in this study are the serving behaviors and the help to keep the privacy. The partners also helped the men to transport to seek medical treatment and assisted the family finance. This statement was expressed by nine men participants who 
mentioned that their sexual need seemed to be fulfilled by the services from their partner. Sexual desire is not always like to be invited to coitus, but it can be in the form of small behaviors given by the couple without any previous communication.

\section{The various perceived stimuli that could increase sexual desire}

The results of the study revealed that males are the ones who are more dominant to call their couple to have sex. The role of men as a husband or a boyfriend in this context is considered as natural that they are more active in sexual activity. On the other hand, the women participants preferred to give a certain code or body language when they wanted to ask her husband to have sex. Even though they had married, women participants mentioned that they felt ashamed to convey their desire directly. Men sexual arousal is readily affected by short stimuli as the influence of an object or fantasies, while passion of female is more influenced by a psychological state as a convenience and the connection in a relationship (Sine, 2013).

The partner's attractiveness is perceived as one of encouragement or stimuli for sexual intercourse. Some married men in this study mentioned that sexual passion is influenced by the looks and ways of dressing of their spouse. A porn video was also said to increase the sexual desire of the participants since it can be a new inspiration for them when having sex. Watching porn video with couples, discussing the favored position and movement can illustrate both sides about what is wanted by each other, and it is sometimes difficult to say in words. By understanding what is wanted by the couple, sexual satisfaction in a relationship can be increased (Gorman, 2014).

\section{The perceived factors that can incapacitate ability and quality of sexual intercourse}

The results of the study revealed that the habits to consume alcohol and ecstasy could decrease the sexual ability of PLWHA. The couples who had a sexual intercourse after consuming alcohol or ecstasy mentioned that they experienced erectile dysfunction and early ejaculation. Alcohol and ecstasy are a depressant substance that can affect the workings of the brain, respiratory and circulatory. Alcohol and drugs in the body hinder receptor on the brain working system that plays a role in delivering stimulation of and to the brain and the peripheral nervous system. Sexual stimulation that is received through sight, hearing, touching, and mind will be very slowly addressed by the brain so that the muscles around the artery of corpus cavernosum are not stimulated well, and the vein of the penis is not closing so that the erection is indefensible. The burden on the mind of being endured can decrease the sexual desire. The unclear family plan was indicated to contribute to stress that occasionally occurred and saddled the minds of the participants. Also, a disappointing experience in early diagnosis of HIV/AIDS and some other unpleasant experiences could be the traumas that occasionally disrupt the mind of the participants.

ARV treatment had some side effects that can decrease the sexual ability of PLWHA. Complaints like the decline in sexual arousal, erectile disorder, and early ejaculation also occurred after the participants started to have the ARV treatment. The influence of ARV to erectile dysfunction is still being controversy; whether it directly be the cause of erectile dysfunction or not. However, the ARV treatment indirectly contributes to 
increasing the weight, circulation lipids, glycemic and sent down serum testosterone which can increase the risk of endothelium dysfunction. Protease inhibitors especially Norvir and Indinavir are reported to exacerbate erectile dysfunction. However, this statement was delivered through a case study that needs for evidence from further research (Santi, Brigante, Zona, Guaraldi \& Rochira, 2014).

The length of marriage was also identified to be a reason for a declined sexual activity and sexual satisfaction of PLWHA. The average length of marriage for seven years with the couple monotonously and the absence of sex variations become a reason for the boredom for sexual intercourse. Basow (2013) stated that individuals' misunderstanding after marriage is that they maintain the satisfaction of the relations than the individuals. Many of them are still concerned with individual satisfaction and want to be understood instead of understanding others, for example, the practice of sex position and certain movements which are not necessarily enjoyed by them. Træen (2010) also argued that the cause of a declined sexual activity in married participants for ten years was the boredom with a partner and the experience of dissatisfaction when having sex. The participants experiencing boredom in having sex mentioned that they did not love their couple again and stated their desire to find a new partner.

The participants are aware of the importance of the use of a condom to prevent the transmission of the virus and sexually transmitted diseases (STDs) to their couple. Thus they tried an easy access to use the condoms provided for free by the foundation. The majority of men participants often complained of the use of condom for various reasons. Eight participants mentioned that the use of condom gave an effect in the change of touching sensation when having sex. They expressed their desire to try to have sex without using a condom. However, the recommendation from the foundation and their partner made them obedient, and they preferred to have sexual intercourse by using a condom though they could have decreased satisfaction. An early refusal to have sex can also decrease the satisfaction that the men participants feel over having sex. It was perceived by the majority of men who expressed emotional response of anger, upset and disappointment when receiving a denial from their wife. It also becomes a reason for them that they do not have a good time for having sex. The expression of refusal through improper communication can result in one side being hurt, disappointed, and angry. Refusal of having sex is no longer painful if the rejection is delivered in good communication. Communication had an important role in keeping the harmony in a relationship (Jones, 2016).

\section{The efforts to increase sexual capability and quality}

The results of the study revealed some self-efforts conducted by the participants to increase their sexual satisfaction. Frequently increased sexual intercourse can cause the occurrence of boredom. For that reason, the participants handled it by sexual intercourse schedule so that it is not so much to do. Besides, trying new position variations and place also provides new atmosphere when they are having sex. The participants also realized the need for good communication with the couples. They should be mutually opened to discussing the problems, and therefore they can achieve satisfaction together. 
A study conducted in Taiwan about the fulfillment of woman sexual need during pregnancy also revealed that various sexual positions as self-efforts could increase the quality of sexual intercourse. The majority of pregnant women preferred the positions of "man on top," "at the side," and "woman on top" (Lee, Lin, Wan \& Liang, 2010). According to the Cosmo Kama Sutra, sexual positions "women on top" is often chosen by the majority of men who fantasize with the aggressiveness from their spouse. The position demands a woman to move more actively and give the phase of taking rest to the man so that he will not feel more tired (Collins, 2001).

Male participants stated that they have "rituals" before having sexual intercourse with their couple. It occurred especially because the men had an experience of suffering from sexual dysfunction such as declined sexual arousal, erectile disorder, and early ejaculation. The participants believed in consuming the foods like eggs and mutton to increase their passion and stamina. The participants also consumed some stamina enhancing medicines, tissue enhancers, and traditional massage as the efforts to increase the erectile capacity when having sex. The substances that could increase sexual desires are known as aphrodisiacs. The aphrodisiacs sourced from plants and animals can be used for the enhancement of sexual desire (Shamloul, 2010). Sildenafil as an aphrodisiac is commonly used to address the erectile disorder. This is evidenced by a study in China involving four thousand people with an impaired erection. After using sildenafil an hour before having sex for three days, the majority of participants showed more erection hardness by the score of 3 to 4 . This outcome indicated the effectiveness of sildenafil to overcome the problem of erection (Zhang et al., 2014).

\section{CONCLUSION}

This study identified five themes related to the lived experiences of PLWHA, i.e., the fulfillment of the sexual need of PLWHA, the roles of partner, the perceived stimuli increasing sexual desire, the perceived factors incapacitating the ability and quality of sexual desire, and the efforts to increase sexual capability and quality of PLWHA. Despite having a virus, after undergoing anti-retroviral (ARV) treatment, PLWHA felt healthier, and thus they could meet their sexual need. The results of this study are expected to become a basic consideration for developing promotional health programs for PLWHA, developing curriculum related to sexuality aspects in PLWHA, and facilitating students to learn more about the case of sexual need.

\section{REFERENCES}

Adekanle, D. A., Olowookere, S. A., Adewole, A. D., Adeleke, N. A., \& Ijadunola, M. Y. (2015). Sexual experiences of married HIV positive women in Osogbo, Southwest Nigeria: role of inappropriate status disclosure. BMC Women Health. 15:6.

Basow, M. K., (2013). The role of sexual satisfaction in couple relationship satisfaction, individual stress and quality of life (Doctoral dissertation). The City University of New York.

Bouhnik, A. D., Preau, M., Schiltz, M. A., Obadia, Y., \& Spire, B. (2008). Sexual difficulties in people living with HIV in France. AIDS Behaviour. 12, 670-676. 
Chama, C., Morrupa, J., and Gashau, W. (2007). Sex and reproduction among HIVinfected people in Maiduguri, Nigeria. Journal of Obstetrics and Gynecology. 27(8): 812-815.

Cohen, S. (2004). Social relationship and health. Am Psychol, 59(8):676-86.

Collazos, J. (2007). Sexual dysfunction in the highly active antiretroviral therapy era. AIDS Rev, 9, 237-45.

Collins, L. (2001). Cosmo Kama Sutra. Cosmopolitan. Retrieved from http://search.proquest.com/docview/199297843?accountid=17242.

Coyle, K. K., Anderson, P. M., Franks, H. M., Glassman, J., Walker, J. D., \& Charles, V. E. (2014). Romantic relationships: an important context for HIV/STI and pregnancy prevention programmes with young people. Sex Education, 14(5), 582596.

Craft, M. S., and Serovich, J. M. (2008). Sexual need fulfillment in the relationships of straight and bisexual men with HIV. AIDS Education and Prevention, 20(3), 2390248.

Darbes, L. A., Chakravarty, D., Bougher, S. C., Neilands, T. B., \& Hoff, C. (2011). Partner-provided social support influences choices of risk reduction strategies in gay male couples. AIDS Behaviour, 16:159-167.

DeLaune, S. C., \& Ladner, P. K. (2011). Fundamentals of Nursing: Standards \& Practice Fourth Edition (4 th). Delmar Cengange Learning.

Directorate General of Disease Control and Environmental Health, Republic of Indonesia. (2014). Situasi dan Analisis HIV/AIDS [Situation and Analysis of HIV/AIDS]. Retrieved on 6 November 2015 from http://www.depkes.go.id/resources/Infodatin\%20AIDS.pdf

Fane, M., Bensghir, R., Sbai, S., Chakib, A., Kadiri, N., Ayouch, A., ... Himmich, H. (2011). Quality of sexual life for people living with HIV (PLWHA). Sexologies 20(3), 158-162.

Gorman, S. (2014). Porn sex vs. real sex: exploring pornography's impact on sexual behaviors, attitudes, and relationships (Doctoral dissertation). Department of Sociology, Georgia State University.

Hummel, C. L. (2010). Impact of sexual frequency on sexual satisfaction, relationship satisfaction, and self-esteem (Master's thesis). University of Victoria.

International Council on Human Rights Policy. (2009). Sexuality and human rights. Geneva: Grand-Montfleury.

Joint United Nations Programme on HIV/AIDS. (2015). AIDS by the number 2015. Retrieved

from http://www.unaids.org/en/resources/documents/2015/AIDS_by_the_numbers_201 5 , on 20 December 2015.

Jones, A. C. (2016). The role of sexual communication in committed relationships (Master's Thesis). Utah State University.

Kaplan, R. L. (2011). Living with HIV/AIDS in Lebanon: Women's perceptions of meaning. ProQuest Dissertations and Theses, 203. Retrieved from http://search.proquest.com/docview/892777681?accountid=17242

Lee, J. T., Lin, C. L., Wan, G. H., \& Liang, C. C. (2010). Sexual positions and sexual satisfaction of pregnant women. Journal of Sec \& Marital Therapy, (36), 408420. https://doi.org/10.1080/0092623X.2010.510776 
Miller, A. M., Kismödi, E., Cottingham, J., \& Gruskin, S. (2015). Sexual rights as human rights: A guide to authoritative sources and principles for applying human rights to sexuality and sexual health. Reproductive Health Matters, 23(46), 16-30. https://doi.org/10.1016/j.rhm.2015.11.007

Muhanguzi, F. K. (2015). "Sex is sweet": Women from low-income contexts in Uganda talk about sexual desire and pleasure. Reproductive Health Matters, 23(46), 6270. https://doi.org/10.1016/j.rhm.2015.11.012

National Institute of Mental Health. (2015). Stress and depression. Retrieved from https://www.nimh.nih.gov/stessanddepression on 10 May 2016.

National Population and Family Planning Board. (2006). Materi Konseling: Buku saku bagi petugas lapangan program $K B$ nasional [Counseling materials: a pocketbook for field officers of national family planning]. Jakarta: National Population and Family Planning Board.

Paul, K., Turek, F. W., \& Kryger, M. H. (2008). Sleep, stress and sex. Journal of Women's Health, 1201-1208. https://doi.org/10.1089/jwh.2008.0841

Qi-jian, S., Yi-Zhong, L., Fei-li, L., Jian, X., \& Xin, D. (2014). Polyactin A increases CD4 T-cells counts in HIV-infected individuals with insufficient immunologic response to highly active antiretroviral therapy. International Journal of STD \& AIDS 25(1), 24-28.

Rowland, D. L., \& Incrocci, L. (2008). Handbook of sexual and gender identity disorders. John Wiley \& Sons, Inc.

Santi, D., Brigante, G., Zona, S., Guaraldi, G., \& Rochira, V. (2014). Male sexual dysfunction and HIV - a clinical perspective. Nat Rev Urol, 11(2), 99-109. https://doi.org/10.1038/nrurol.2013.314

Shamloul, R. (2010). Natural Aphrodisiacs. Journal of Sexual Medicine, (7), 39-49. https://doi.org/10.1111/j.1743-6109.2009.01521.x

Shapiro, K., \& Ray, S. (2007). Sexual health for people living with HIV. Reproductive Health Matters; 12(29 Supplement):67-92.

Sine, R. (2013). Sex drive: how do men and women compare? Retrieved from http://www.webmd.com/sex/features/sex-drive-how-do-men-women-compare on 2 December 2016.

Struart, G.W., \& Laraia, M. T. (2005). Principles and practice of psychiatric nursing (8th ed). Missouri: Mosby Inc.

Træen, B. (2010). Sexual dissatisfaction among heterosexual Norwegians in couple relationships, Sexual and Relationship Therapy, 25(2), 132-147. https://doi.org/10.1080/14681991003622518

Zhang, K., Xu, B., Liu, D., Wang, X., Zhu, J., Deng, C., ... Jiang, H. (2014). Sildenafil improves erectile hardness in Chinese men with erectile dysfunction: a real-life study analyzed on age stratification. Urology, 83(4), 831-836. https://doi.org/10.1016/j.urology.2013.12.007 